\title{
Finite Element Investigation of the Influence of SiC Particle Distribution on Diamond Cutting of SiCp/AI Composites
}

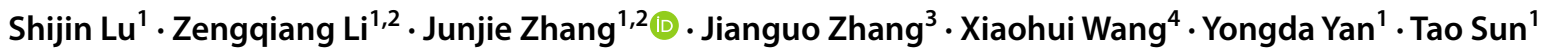

Received: 5 June 2020 / Revised: 30 July 2020 / Accepted: 2 September 2020 / Published online: 25 September 2020

(C) The Author(s) 2020

\begin{abstract}
Characteristics of internal microstructures have a strong impact on the properties of particulate reinforced metal composites. In the present work, we perform finite element simulations to elucidate fundamental mechanisms involved in the ultraprecision orthogonal cutting of aluminum-based silicon carbide composites $(\mathrm{SiCp} / \mathrm{Al})$, with an emphasis on the influence of particle distribution characteristic. The SiCp/Al composite with a particle volume fraction of $25 \mathrm{vol} \%$ and a mean particle size of $10 \mu \mathrm{m}$ consists of randomly distributed polygon-shaped $\mathrm{SiC}$ particles, the elastic deformation and brittle failure of which are described by the brittle cracking model. Simulation results reveal that in addition to metal matrix tearing, cuttinginduced particle deformation in terms of dislodging, debonding, and cracking plays an important role in the microscopic deformation and correlated machining force variation and machined surface integrity. It is found that the standard deviation of particle size to the mean value has a strong influence on the machinability of microscopic particle-tool edge interactions and macroscopically observed machining results. The present work provides a guideline for the rational synthesis of particulate-reinforced metal composites with high machinability.
\end{abstract}

Keywords $\mathrm{SiCp} / \mathrm{Al}$ composites $\cdot$ Orthogonal cutting $\cdot$ Particle-tool interaction $\cdot$ Particle distribution $\cdot$ FE simulation

\section{Introduction}

Aluminum-based silicon carbide composites ( $\mathrm{SiCp} / \mathrm{Al})$ have been widely used in the aerospace, automotive, machinery, and electronics industries for their unique physical and mechanical properties [1-3]. While mechanical machining is normally required to achieve desired shapes with considerable accuracy, recently cutting technique has also been proposed to process $\mathrm{SiCp} / \mathrm{Al}$ composites for its high geometrical accuracy and high efficiency [4]. However, the

Junjie Zhang

zhjj505@gmail.com

1 Center for Precision Engineering, Harbin Institute of Technology, Harbin 150001, China

2 Technology and Innovation Research Center of Jiangyan Economic Development Zone, Taizhou 225300, China

3 State Key Laboratory of Digital Manufacturing Equipment and Technology, School of Mechanical Science and Engineering, Huazhong University of Science and Technology, Wuhan 430074, China

4 School of Mechanical Engineering, University of Jinan, Jinan 250022, China poor synergetic deformation behavior between hard-brittle $\mathrm{SiC}$ reinforcement and soft-ductile $\mathrm{Al}$ matrix leads to low machinability of $\mathrm{SiCp} / \mathrm{Al}$ in cutting process. In particular for the ultra-precision diamond cutting with depths of cut (DOCs) comparable to particle sizes, the underlying machining mechanisms of $\mathrm{SiCp} / \mathrm{Al}$ are complex due to the strong size effect.

The mechanical properties of SiCp/Al strongly rely on the geometrical characteristics of internal microstructures. For instance, the Young's modulus of $\mathrm{SiCp} / \mathrm{Al}$ composites containing $70 \mathrm{vol} \%$ and $30 \mathrm{vol} \% \mathrm{SiC}$ particles is $230 \mathrm{GPa}$ and $110 \mathrm{GPa}$, respectively [5]. Accordingly, the machinability of $\mathrm{SiCp} / \mathrm{Al}$ composites is greatly affected by intrinsic material parameters such as size and volume fraction of $\mathrm{SiC}$ particles. Therefore, a thorough understanding of the influences of geometrical parameters of $\mathrm{SiC}$ particles on the machining of $\mathrm{SiCp} / \mathrm{Al}$ is required. Teng et al. performed cutting experiments of micro- and nano-particle-reinforced $\mathrm{SiCp} / \mathrm{Al}$ composites. They found that nanoparticles are less likely to break and more likely to form continuous chips during cutting processes than microparticles, which are easy to break and tend to form discontinues chips. Also, a better machined surface quality can be obtained from nanoparticle-reinforced metal 
matrix composites (MMCs) than microparticle-reinforced MMCs [6]. Cheung et al. experimentally investigated the effect of size and volume fraction of $\mathrm{SiC}$ reinforcement in ultra-precision machining of Al6061/SiC composites, and reported that a better surface finish can be achieved with thinner reinforcements or smaller volume fraction of reinforcements [7, 8]. Fathipour et al. performed finite element (FE) simulations to investigate the effect of volume fraction of $\mathrm{SiC}$ particles on chip formation in $\mathrm{SiCp} / \mathrm{Al}$ cutting, and indicated that the size of saw-tooth chip decreases with increasing volume fraction of $\mathrm{SiC}$ particles [9]. Sandhiya et al. carried out FE simulations to investigate the influences of volume fraction, size, shape, and distribution of SiC particles on particle-tool edge interactions, chip formation, and residual stress pattern in $\mathrm{SiCp} / \mathrm{Al}$ cutting. They concluded that the shape of $\mathrm{SiC}$ particles has a strong influence on chip morphology: while circular particles undergo minimum squeezing and are likely to debonding with matrix, hexagonal particles are likely to break [10].

Although previous studies have provided valuable insights into the cutting process of $\mathrm{SiCp} / \mathrm{Al}$ composites, they mainly focused on the influence of size and volume fraction of $\mathrm{SiC}$ particles, and there is no work reported on the influence of particle distribution characteristics. In particular, the size of $\mathrm{SiC}$ particles in real microstructure of $\mathrm{SiCp} / \mathrm{Al}$ specimen follows a Gaussian distribution. Wang et al. found that the size of $\mathrm{SiC}$ particles with Gaussian distribution ranges from 2 to $18 \mu \mathrm{m}$ with a mean value of $10 \mu \mathrm{m}$ in $\mathrm{SiCp} / \mathrm{Al}$ specimen [11]. While the influence of $\mathrm{SiC}$ particle size on the cutting of $\mathrm{SiCp} / \mathrm{Al}$ has been widely demonstrated, the standard deviation of $\mathrm{SiC}$ particle size also has a strong influence on the machinability of $\mathrm{SiCp} /$ $\mathrm{Al}$ due to different particle-tool edge interactions [12]. Furthermore, simplified assumptions on $\mathrm{SiC}$ particles, such as setting particles as linear elastomers, arranging particle shape as sphere, assigning uniform particle size and distribution, etc. [13-16], have been widely adopted in previous FE simulations, which inevitably deteriorate the accuracy of prediction results. For instance, stress pattern built in the vicinity of reinforcements are significantly different for spherical and polygon particles, which may also result in different machining behaviors of the composites.

Therefore, in the present work, we establish a 2D FE model of diamond cutting of $\mathrm{SiCp} / \mathrm{Al}$ composites with 25 vol\% $\mathrm{SiC}$ particles. Reinforced $\mathrm{SiC}$ particles with arbitrary polygonal shapes are randomly distributed, and $\mathrm{SiC}$ particle sizes ranging from 5 to $15 \mu \mathrm{m}$ follow a Gaussian distribution. Furthermore, $\mathrm{SiC}$ particles described by the brittle cracking model are allowed to undergo elastic deformation and brittle failure. The underlying cutting mechanisms of $\mathrm{SiCp} / \mathrm{Al}$, in particular particle-tool interactions and their correlations with machining results, are revealed. Furthermore, four standard deviations of $\mathrm{SiC}$ particle distribution, while keeping a constant mean value of $10 \mu \mathrm{m}$, are considered to investigate the influence $\mathrm{SiC}$ particle distribution characteristics on the cutting of $\mathrm{SiCp} / \mathrm{Al}$.

\section{Methodology}

Figure 1a shows the 2D FE model of orthogonal cutting of $\mathrm{SiCp} / \mathrm{Al}$ composites, which is composed of a $\mathrm{SiCp} / \mathrm{Al}$ specimen and a diamond tool. The specimen has a dimension of $120 \mu \mathrm{m}$ in length and $50 \mu \mathrm{m}$ in height, which is extracted from a large sample with a dimension of $250 \mu \mathrm{m}$ in length and $250 \mu \mathrm{m}$ in height, as shown in Fig. 1b. The large sample consists of randomly distributed polygonshaped $\mathrm{SiC}$ particles with a volume fraction of $25 \mathrm{vol} \%$, and the equivalent diameter of $\mathrm{SiC}$ particles follows a Gaussian distribution [11]:
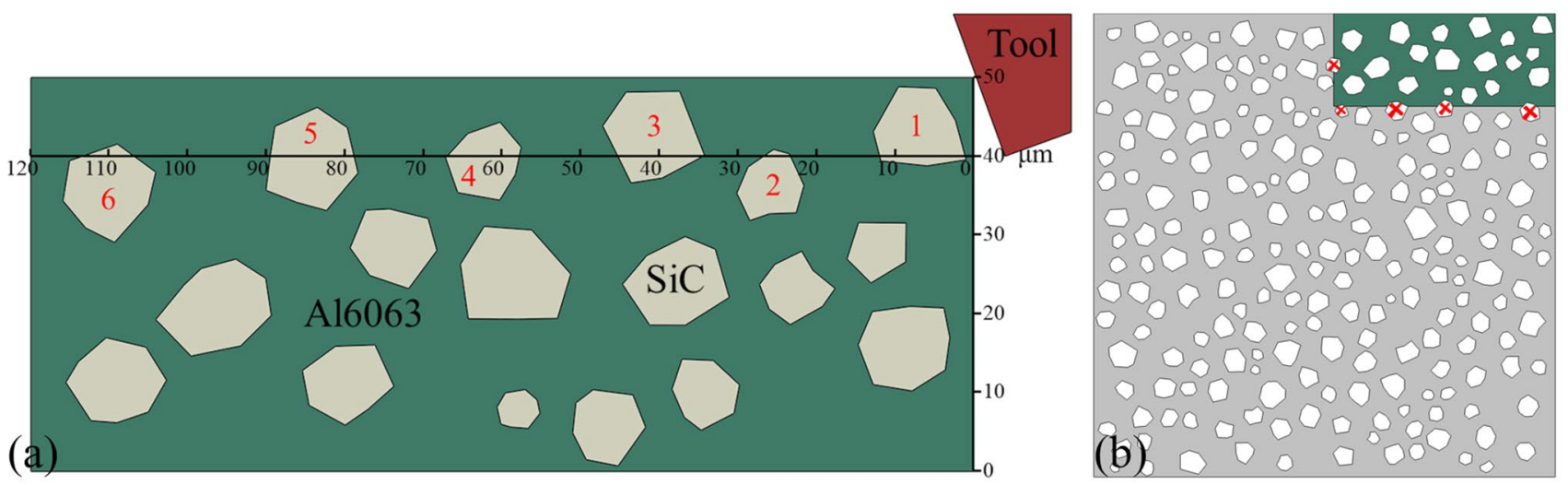

Fig. 1 FE modeling of orthogonal cutting of SiCp/Al composites with a mean value of 10 and a standard deviation of 2. a Geometry between tool path and involved particles; $\mathbf{b}$ large model of SiCp/Al sample 
$p(\bar{d})=0.0581+\frac{40.2915}{\operatorname{Var}} \cdot \exp \left(-0.5 \times\left(\frac{\bar{d}-\mathrm{Ex}}{\operatorname{Var}}\right)^{2}\right)$

where Ex is the mean value that is equal to $10 \mu \mathrm{m}$, Var is the standard deviation, and $d$ is the equivalent diameter of $\mathrm{SiC}$ particles. In the present work, four values of Var are considered, as 1, 1.5, 2, and 2.5, respectively. Figure 2 a plots the corresponding volume fractions of the equivalent particle diameters for the four standard deviations, which shows that the statistical centralization of particle sizes to the mean value is increased with increasing value of Var. Accordingly, Fig. $2 \mathrm{~b}-\mathrm{e}$ shows microstructure configurations of the $\mathrm{SiCp} /$ $\mathrm{Al}$ specimen with different standard deviations.

The $\mathrm{SiCp} / \mathrm{Al}$ specimen is equally meshed by CPE4R element type with an element size of $0.5 \mu \mathrm{m}$. Both the left side and the bottom of the specimen are fixed. SiC particles and $\mathrm{Al}$ matrix are established as independent parts. While the interfacial bonding between $\mathrm{SiC}$ particle and $\mathrm{Al}$ matrix is represented by tie constraints, the failure of the $\mathrm{Al}$ matrix around $\mathrm{SiC}$ particles leads to the debonding of the particle-matrix interface. The simulated diamond tool is treated as a discrete rigid body by ignoring tool wear within the short cutting length of $120 \mu \mathrm{m}$. The tool has a rake angle of $-20^{\circ}$ and a flank angle of $20^{\circ}$. In the FE simulations of orthogonal cutting process, the diamond tool cuts the specimen surface with a constant DOC of $10 \mu \mathrm{m}$ and a constant cutting speed of $0.3 \mathrm{~m} / \mathrm{min}$.

The elasto-plastic deformation of Al6063 matrix is described by the Johnson-Cook ( $\mathrm{J}-\mathrm{C})$ model, and a $\mathrm{J}-\mathrm{C}$ damage criteria based on equivalent plastic strain is employed to achieve material separation and chip formation $[17,18]$. The elastic deformation and brittle failure of $\mathrm{SiC}$ particles are described by the brittle cracking model implemented in ABAQUS [19], and the detailed model parameters come from Ref. [20]. Table 1 lists the physical properties of the Al6063 matrix and $\mathrm{SiC}$ particles used in the FE simulations. Table 2 lists the parameters of the $\mathrm{SiC}$ brittle cracking model. The surface-to-surface contact is used to describe

Table 1 Physical parameters of A16063 and SiC

\begin{tabular}{lll}
\hline Material properties & Al6063 [17] & $\mathrm{SiC}[19]$ \\
\hline Thermal conductivity $W /(\mathrm{mm} \mathrm{K})$ & 193 & 81 \\
Density $\left(\mathrm{kg} / \mathrm{m}^{3}\right)$ & $2.7 \times 10^{3}$ & $3.13 \times 10^{3}$ \\
Elastic modulus $(\mathrm{GPa})$ & 68.9 & 420 \\
Poisson's ratio & 0.33 & 0.14 \\
Specific heat capacity $J /(\mathrm{kg} \mathrm{K})$ & 900 & 427 \\
Thermal expansion coefficient $\left(\mathrm{K}^{-1}\right)$ & $2.18 \times 10^{-5}$ & $4.9 \times 10^{-6}$ \\
\hline
\end{tabular}

Fig. $2 \mathrm{SiCp} / \mathrm{Al}$ composites specimen used in this paper. a Gaussian curve of the relationship between the equivalent diameter of reinforced $\mathrm{SiC}$ particles and corresponding frequency; Microstructure with Var of b 1, c 1.5, d 2 and e 2.5
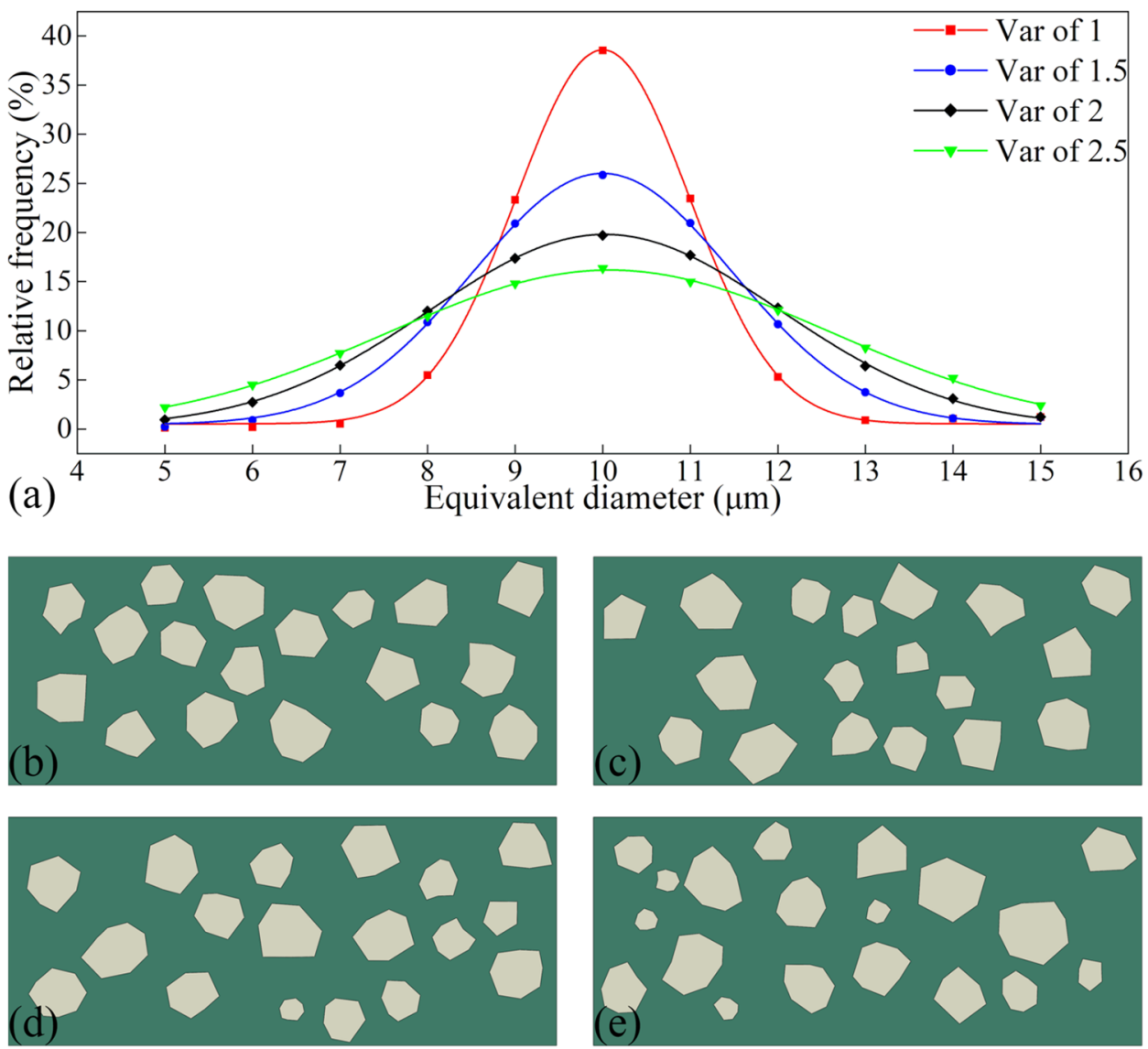
Table 2 Parameters of the brittle cracking model for $\mathrm{SiC}$ particles [20]

\begin{tabular}{llll}
\hline$\sigma_{0}(\mathrm{MPa})$ & $G_{\mathrm{f}}^{\mathrm{l}}\left(\mathrm{J} / \mathrm{m}^{2}\right)$ & $p$ & $\varepsilon_{\max }^{\mathrm{ck}}$ \\
\hline 1500 & 30 & 1 & 0.001
\end{tabular}

the interaction between tool and $\mathrm{Al}$ matrix, as well as the interaction between the tool and $\mathrm{SiC}$ particles. Specifically, the first surface is selected as the external surface of the cutting tool, and the second surface is selected as the node type, which includes all nodes of $\mathrm{SiC}$ particles and $\mathrm{Al}$ matrix. The friction coefficient between the tool and $\mathrm{SiCp} / \mathrm{Al}$ during machining is 0.45 . It should be noted that the consideration of the interaction of removed $\mathrm{SiC}$ particles with $\mathrm{Al}$ matrix may provide a more accurate description of the cutting force, chip formation, and stress distribution. Since current work mainly focuses on the influence of $\mathrm{SiC}$ particle-tool interactions on the cutting process with a relatively small DOC, removed $\mathrm{SiC}$ particle-Al matrix interaction after material failure is not considered for simplifying the FE model.

\section{Results and Discussion}

\subsection{Cutting Mechanisms of SiCp/AI Composites}

FE simulation of orthogonal cutting of $\mathrm{SiCp} / \mathrm{Al}$ composites with a Var of 2 is performed to elucidate the involved cutting mechanisms. Figure 1a shows that there are six SiC particles interacting with the tool path within a cutting distance of $120 \mu \mathrm{m}$. According to the relative positions of cutting tool edge with respect to the center of mass (COM) of involved

$\mathrm{SiC}$ particles, the particle-tool edge interactions can be categorized into three scenarios: the tool edge is above particles 2 and 6 (herein referred to as Upper), the tool edge traverses particles 4 and 5 (herein referred to as Middle), and tool edge is below particles 1 and 3 (herein referred to as Lower). It should be noted that the influence of $\mathrm{SiC}$ particle-tool interaction on cutting results is notably for either small or large cutting depth. Dabade et al. indicated that particle fracture and plowing also exist in $\mathrm{SiCp} / \mathrm{Al}$ cutting with a large DOC of $1 \mathrm{~mm}$ [21]. Since the equivalent diameter of SiC particles follows a Gaussian distribution and $\mathrm{SiC}$ particles are randomly distributed in an Al matrix, the current FE model is also capable of addressing the influence of the relative position between the tool and particles.

Figure 3 plots variations of cutting force and thrust force with cutting length in the FE simulation of cutting process of $\mathrm{SiCp} / \mathrm{Al}$ composites with a Var of 2. Moreover, each cutting period in the vicinity of individual $\mathrm{SiC}$ particles is highlighted by a green rectangular frame. Figure 3 shows that both the cutting force and thrust force increase with the approaching tool edge towards the particle, and reach local maximum values when cutting is performed on the particle, followed by a decrease due to moving away from the particle. Moreover, the significant fluctuations in both cutting force and thrust force originate from deformation of both $\mathrm{Al}$ matrix and $\mathrm{SiC}$ particles.

Figure 3 also suggests that $\mathrm{SiC}$ particle-tool edge interactions have a strong influence on the evolution of machining force. For particles 1 and 3, which are both above the tool edge, the local maximum value of cutting force for particle 3 is significantly higher than that for particle 1 .

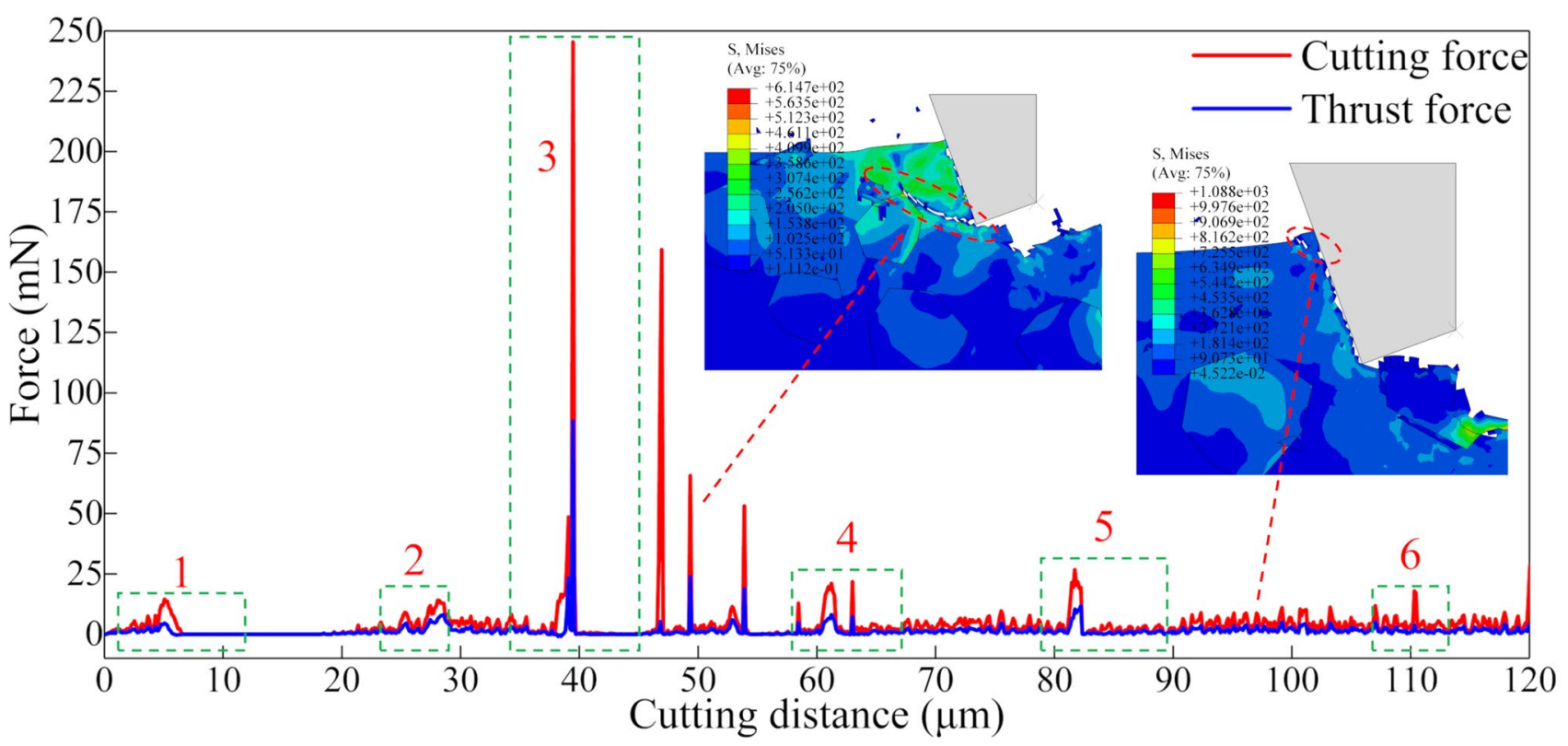

Fig. 3 Variations of cutting force and thrust force with cutting distance in FE simulation of cutting process of SiCp/Al with a Var of 2 
The discrepancy in machining force variation between particles 1 and 3 can be attributed to different deformation behaviors: while particle 1 is completely removed with formed chips, particle 3 undergoes a serious fracture. While particles 4 and 5 are both traversed by the tool edge, the characteristics of cutting force variation are similar. Although particles 2 and 6 are both below the tool edge, the fluctuation of cutting force for particle 2 is more pronounced than that for particle 6 . While the machining force variation for matrix cutting between particles 1 and 2 is smooth, there are strong fluctuations in cutting force for the rest inter-particle cutting. In particular, there is a significant increase of cutting force for the $\mathrm{Al}$ matrix cutting between particles 3 and 4, which is attributed to the bulk removal of $\mathrm{Al}$ matrix. When the $\mathrm{Al}$ matrix between particles 5 and 6 removes in the form of debris, only a slight vibration of cutting occurs. In order to verify whether the FE model adopted is sufficient to reflect the cutting force evolution and surface defect characteristics during the cutting process, a large model with a cutting distance of $250 \mu \mathrm{m}$ is also extracted from Fig. 1b. The other parameters are the same for each model. The derived average cutting force and surface roughness from the model with a cutting distance of $250 \mu \mathrm{m}$ is $4.234 \mathrm{mN}$ and $1.45 \mu \mathrm{m}$, respectively. Correspondingly, the error of average cutting force and surface roughness between the cutting distances of $120 \mu \mathrm{m}$ and $250 \mu \mathrm{m}$ is $4.213 \%$ and $6.618 \%$, respectively. Thus, the model with a small cutting length of $120 \mu \mathrm{m}$ is sufficient to describe cutting force evolution and surface defect characteristics during the cutting process of $\mathrm{SiCp} / \mathrm{Al}$.

Figure $4 \mathrm{a}, \mathrm{b}$ respectively plots the localized variation of cutting force and thrust force in the vicinity of particles 2 and 3 in the FE simulation of cutting process of $\mathrm{SiCp} / \mathrm{Al}$ composite with a Var of 2, and for each particle, four representative points are highlighted by sequential numbers. Furthermore, Fig. 4c, e, g, i and Fig. 4d, f, h, j present cutting configurations of particle 2 and particle 3 at different cutting distances, indicated by numbers shown in Fig. 4a, b, respectively.

Figure $4 \mathrm{c}$ shows that when the tool edge is approaching particle 2, the $\mathrm{Al}$ matrix on the right side of particle 2 is subjected to tensile stress. With the advancement of the tool edge, Fig. 4e indicates that there is tensile stress and compressive stress concentrated in the upper and lower parts of particle 2, respectively, which subsequently leads to the rotation of particle 2 . Further cutting action leads to the failure of $\mathrm{Al}$ matrix under tensile stress, which in turn results in the debonding of particle 2 from the surrounding Al matrix, as shown in Fig. 4g. Figure 4i shows that since particle 2 is partially broken, the particle-tool edge interactions disappear. Figure 4 shows that the cutting force for particle 2 reaches its local maximum value before particle broken, after which the cutting force is reduced accompanied with chip formation.
Figure 4d shows instantaneous maximal principal stress contours of the local specimen after particle 3 is moved forward by a distance of $0.2 \mu \mathrm{m}$. While there is a high concentration of compressive stress in the contact region between tool edge and particle 3 , the Al matrix below particle 3 is subjected to high tensile stress, which indicates that particle 3 has a high tendency to be pulled out. Consequently, the unprocessed surface of $\mathrm{SiCp} / \mathrm{Al}$ specimen is curved compared to the pristine surface, as shown in Fig. 4f. Since the tensile stress value in the bottom of particle 3 is the first to reach the maximum tensile stress limit of $\mathrm{SiC}$, Fig. $4 \mathrm{~h}$ demonstrates that the broken of particle 3 firstly occurs in the opposite end of the $\mathrm{SiC}$ particle-tool edge contact. Finally, particle 3 is completely broken, which is caused by the cutting action, as shown in Fig. 4j. Correspondingly, the cutting force for particle 3 continuously increases to its local maximum value. In this study, the dispersion of $\mathrm{SiC}$ particles into the Al matrix accounts for the discrete chip in the cutting process shown in Fig. 4i, j. Furthermore, the used cutting tool has a negative rake angle, which is not beneficial for continuous chip formation due to compressive stress.

Figure 5a presents the simulated configuration of $\mathrm{SiCp} /$ $\mathrm{Al}$ specimen with a Var of 2 colored by instantaneous maximal principal stress after cutting. In order to clearly show the evolution of $\mathrm{SiC}$ particles before and after the cutting process, positions of the original particles are also presented with red lines. It is intuitively observed from Fig. 5a that there are different failure modes of $\mathrm{SiC}$ particles occurring: complete removal within formed chip composed of $\mathrm{Al}$ matrix (particles 1 and 3); debonding from $\mathrm{Al}$ matrix (particles 4 and 5); crushed particles remaining in Al matrix after being partially broken (particles 2 and 6). The observed different deformation modes of $\mathrm{SiC}$ particles are closely associated with different particle-tool edge interactions based on the geometrical orientations. Moreover, it is found from Fig. 5a that tensile stress exists only in subsurfaces with a depth of $5 \mu \mathrm{m}$, while compression stress appears in areas with greater depths. Figure $5 b$ further plots the profile of machined surfaces in terms of surface height, which indicates that subsurface damage is dominated by particle-matrix debonding (particle 2). Furthermore, the rebound of particle 5 leads to a surface pile up with a height of $4.5 \mu \mathrm{m}$ formed on the machined surface.

\subsection{Influence of SiC Particle Distributions}

To address the influence of $\mathrm{SiC}$ particle distributions on the diamond cutting of $\mathrm{SiCp} / \mathrm{Al}$ composites, FE simulations are performed to investigate the cutting processes of $\mathrm{SiCp} / \mathrm{Al}$ with the other three standard deviations Vars of 1, 1.5, and 2.5, in addition to the Var of 2. The other configuration parameters as well as cutting conditions are the same for each standard deviation Var. 

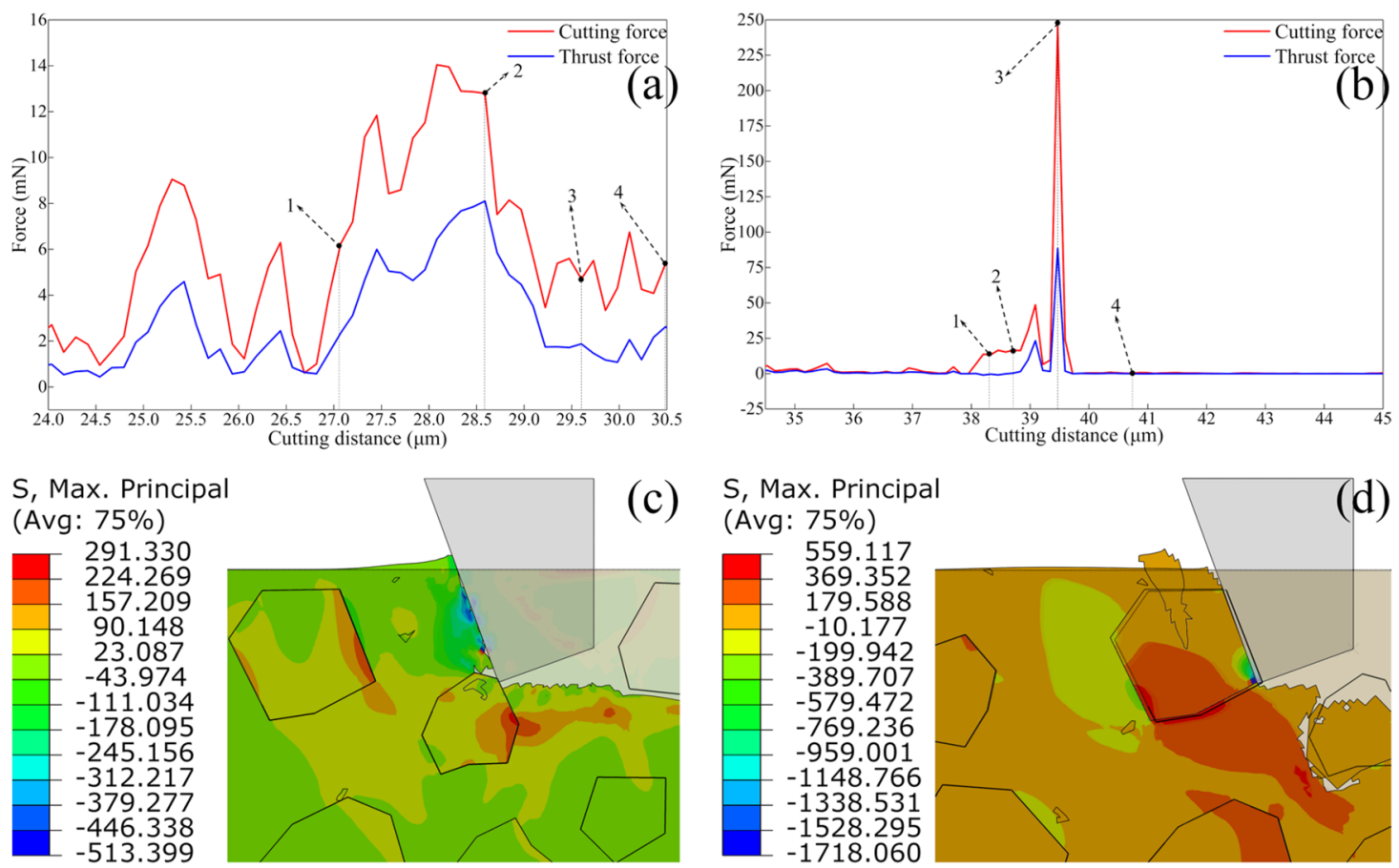

S, Max. Principal (Avg: 75\%)

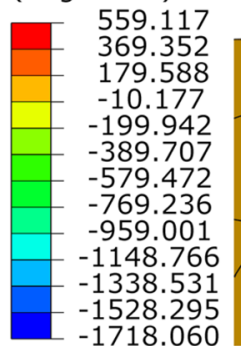

(d)
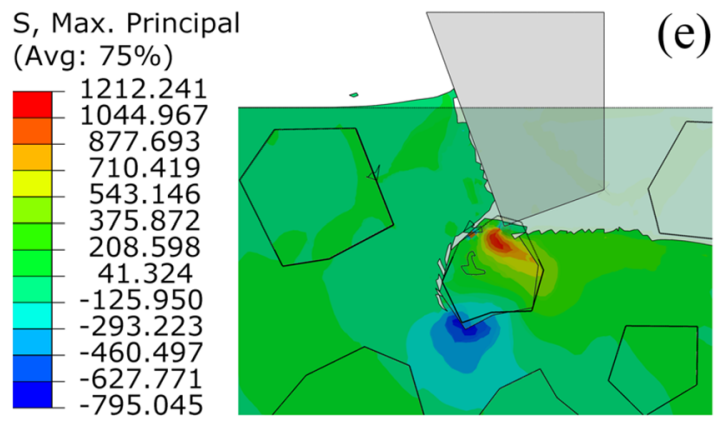

S, Max. Principal

(Avg: 75\%)

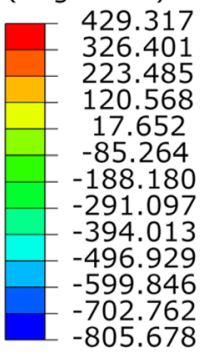

S, Max. Principal (Avg: 75\%)
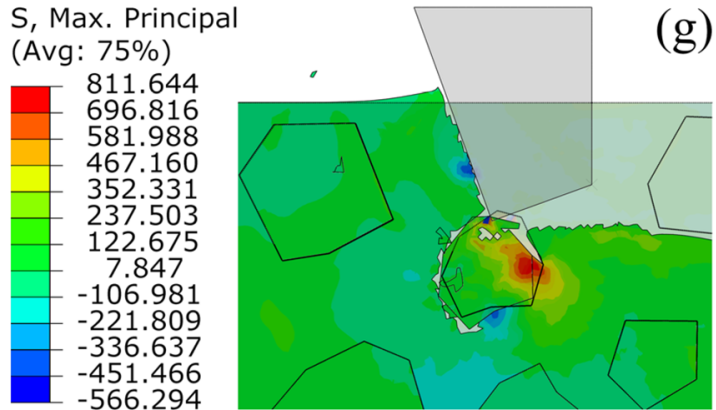

S, Max. Principal

(Avg: 75\%)

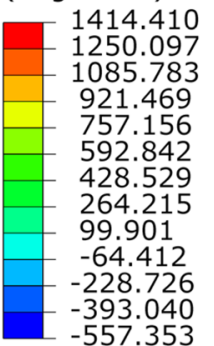

S, Max. Principal (Avg: 75\%)
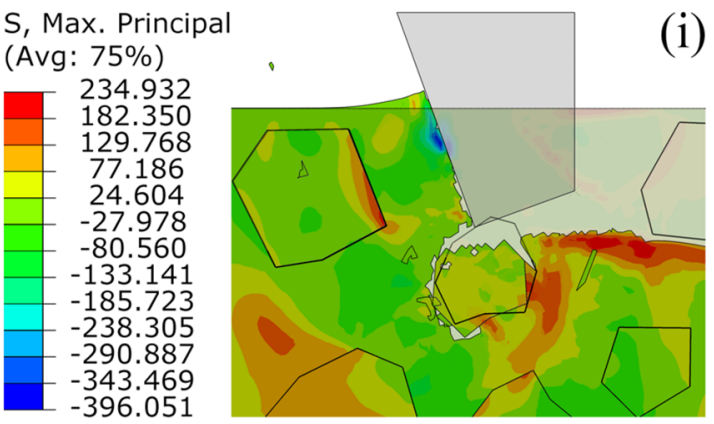

(i)

S, Max. Principal (Avg: 75\%)

\begin{tabular}{|r|}
560.679 \\
\hline \\
502.002 \\
443.324 \\
384.646 \\
325.968 \\
\hline 267.290 \\
208.613 \\
149.935 \\
91.257 \\
32.579 \\
-26.099 \\
-84.776 \\
-143.454
\end{tabular}
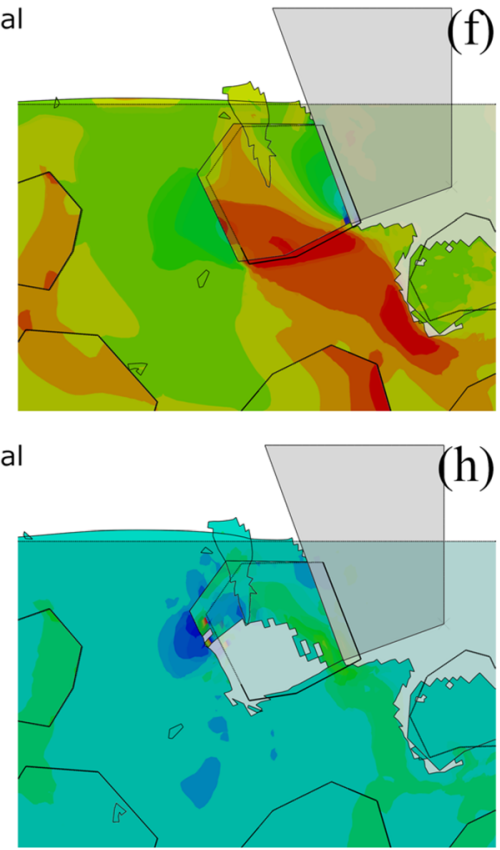

h) 
४Fig. 4 FE simulation results of particle-tool interactions in orthogonal cutting of $\mathrm{SiCp} / \mathrm{Al}$ composites with a Var of 2. Localized variation of cutting force for cutting of a particle 2 and $\mathbf{b}$ particle 3 . Cutting configuration of particle 2 at a cutting distance of $\mathbf{c} 27.1 \mu \mathrm{m}$, e $28.6 \mu \mathrm{m}, \mathbf{g} 29.6 \mu \mathrm{m}$, and $\mathbf{i} 30.5 \mu \mathrm{m}$; cutting configuration of particle 3 at a cutting length distance of $\mathbf{d} 38.35 \mu \mathrm{m}, \mathbf{f} 38.75 \mu \mathrm{m}, \mathbf{h} 39.5 \mu \mathrm{m}$, and $\mathbf{j} 40.8 \mu \mathrm{m}$

Figure $6 \mathrm{a}, \mathrm{b}$ plots variations of cutting force and thrust force for the four Vars, respectively, which indicate a maximum cutting force and thrust force with the Var of 1.5. In addition, since the number of involved $\mathrm{SiC}$ particles on the tool path is the largest for the Var of 1.5 , it can be seen that the number of peaks of both cutting force and thrust force is also the largest. The number of cutting force peaks is the lowest for the Var of 1. Figure 6c plots variations of average cutting force and thrust force with Var. The average cutting force or thrust force for Vars of 1 and 2 are essentially the same, and their values are smaller than those for the other two Vars. Both cutting force and thrust force are maximum for the Var of 1.5.

Figure 7 presents simulated configurations of SiCp/ Al specimen with four different Vars after cutting, which indicates that the maximum compressive stress for the Var of 2.5 is significantly higher than that for the other there Vars. The compressive stress is mainly distributed in the $\mathrm{Al}$ matrix between adjacent $\mathrm{SiC}$ particles, and the connected particles also have a partial compressive stress distribution region. The deformation modes of $\mathrm{SiC}$ particles mentioned in the previous section, such as dislodge, fracture, and dislocation, are also reflected in the cutting results with different value of Vars. Figure $7 d$ shows that the machined surfaces of the first and last particles on the cutting path have similar flatnesses to the machined surface of the surrounding Al matrix for the Var of 2.5, which is conducive to improve machined surface quality of the specimen.

Figure 8a plots the profile of machined surface for the four Vars. While protrusion of the machined surface only occurs for the Var of 2, the Vars of 1.5 and 2.5 have the cavity with the largest depth of $9 \mu \mathrm{m}$. The Var of 1 has the maximum width of cavity of $30 \mu \mathrm{m}$. Figure $8 \mathrm{~b}$ further plots variations of simulated surface roughness for the four Vars. The surface roughness has a maximum value for the Var of 1.5 and a minimum value for the Var of 2. The evolution of surface roughness has the same trend with the average cutting force. Therefore, with the comprehensive consideration of the number of pits and roughness values of the machined surface, the large range of $\mathrm{SiC}$ particle size distribution is beneficial to achieve high machined surface quality.

\section{Conclusions}

In summary, we investigate the machinability of $\mathrm{SiCp} / \mathrm{Al}$ composites in ultra-precision diamond cutting by $2 \mathrm{D} \mathrm{FE}$ modeling and simulation. The simulated SiCp/Al composite consists of randomly distributed polygon-shaped $\mathrm{SiC}$ particles, and the elastic deformation and brittle failure of $\mathrm{SiC}$ particles are described by the brittle cracking model. FE simulation results reveal that the $\mathrm{SiC}$ particle-tool edge interactions have a strong dependence on the geometry between the tool edge and particle position, and also have a close correlation with machined surface integrity. Specifically, while tool-particle interaction occurring in the lower middle part of particles leads to a smooth machined surface due to complete removal of $\mathrm{SiC}$ particles within the formed chip, crushed particles remaining in the Al matrix induced by particle-tool edge interaction occurring in the upper
Fig. 5 FE simulation of machined surface morphology after cutting of $\mathrm{SiCp} / \mathrm{Al}$ composites with a Var of 2. a Configuration of machined surface. $\mathbf{b}$ Profile of machined surface
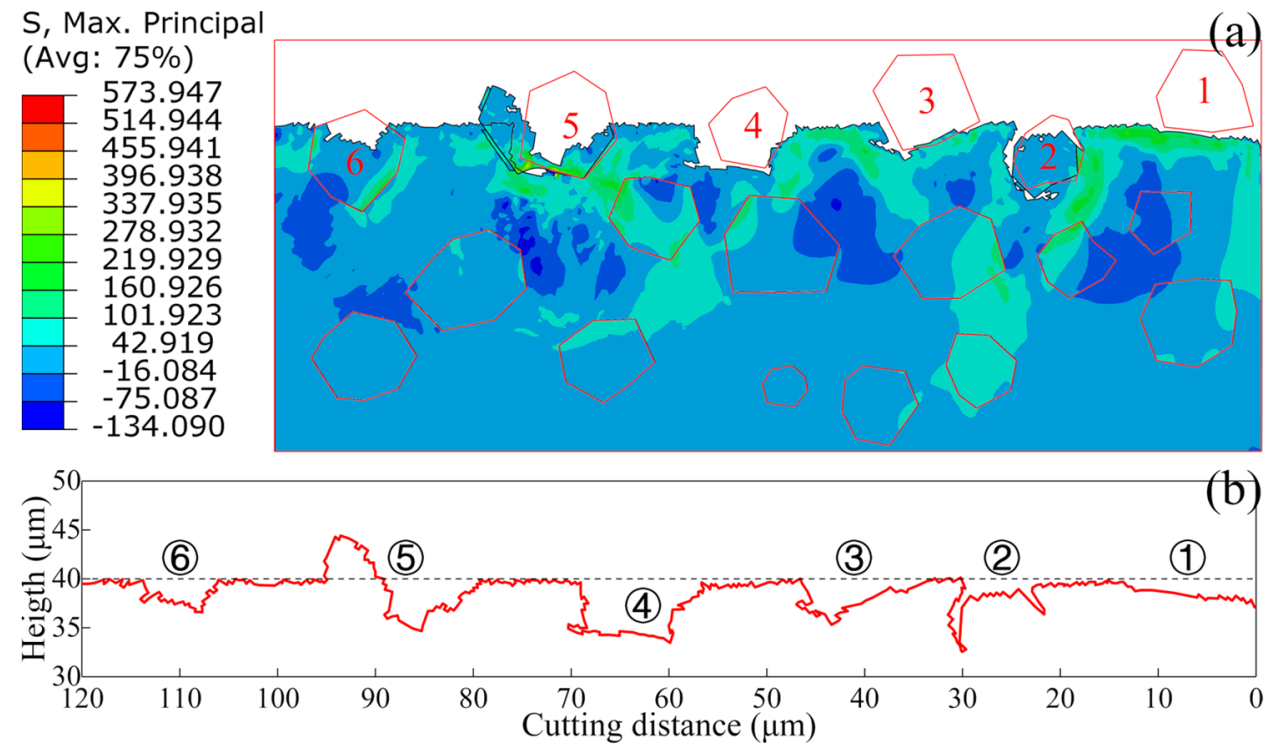
Fig. 6 Variation of machining force in FE simulations of $\mathrm{SiCp} /$ $\mathrm{Al}$ composites with different $\mathrm{SiC}$ particle distributions. a Variation of cutting force; $\mathbf{b}$ variation of thrust force; $\mathbf{c}$ variation of average cutting force and thrust force with standard derivation of $\mathrm{SiC}$ particle size
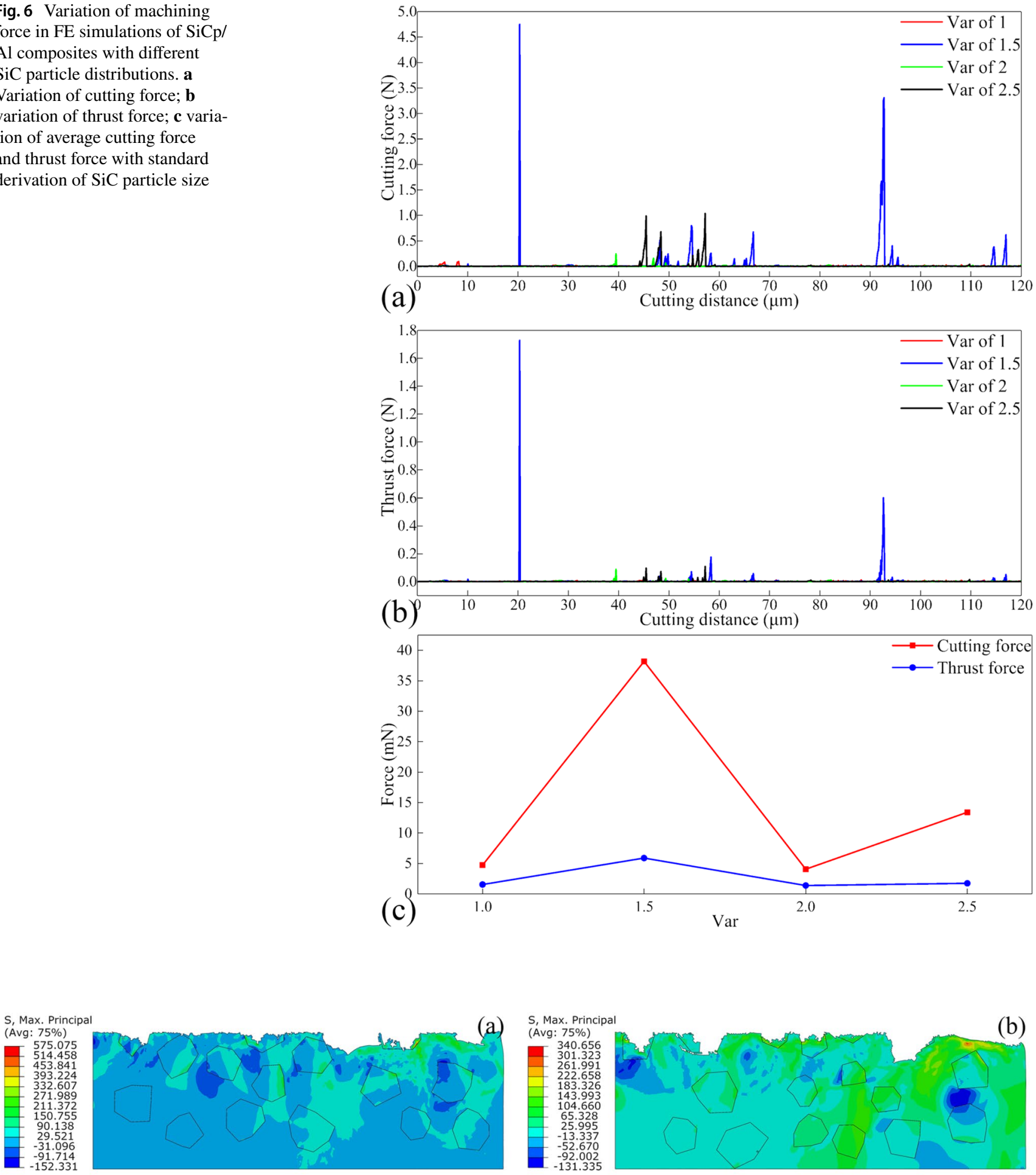

(a) S, Max. Principal

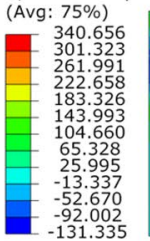

(b)

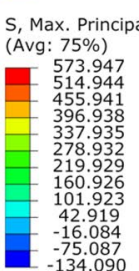

(c)

S, Max. Principal

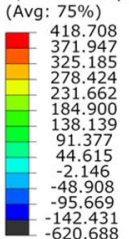

(d)

Fig. 7 Simulated machined surface of $\mathrm{SiCp} / \mathrm{Al}$ composites with different Vars. Configuration of specimen for the Var of a 1; b 1.5; c 2.0; $\mathbf{d} 2.5$ 


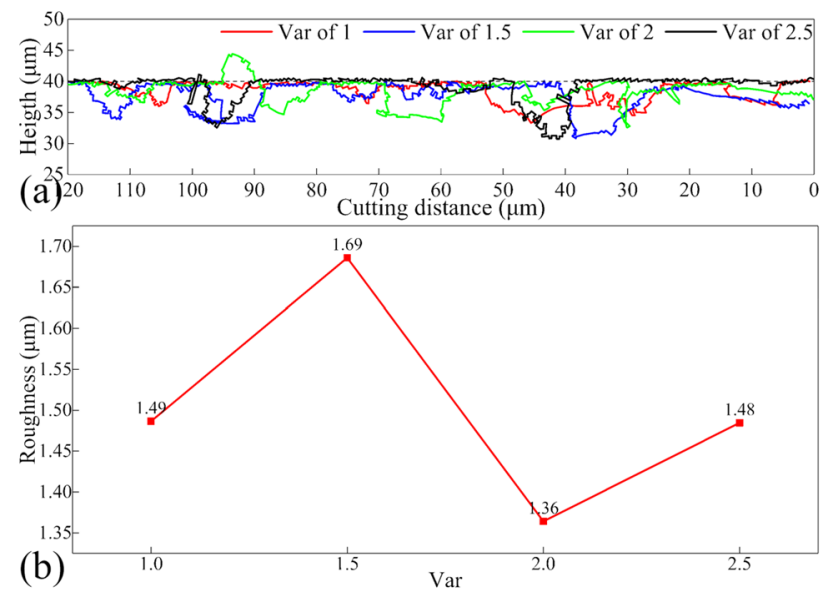

Fig. 8 Characterization of machined surface quality in FE simulations of $\mathrm{SiCp} / \mathrm{Al}$ composites with different $\mathrm{SiC}$ particle distributions. a Profiles of machined surface for the four Vars; $\mathbf{b}$ Variations of surface roughness for the four Vars

middle part of the particles also benefits surface integrity, but debonding of $\mathrm{SiC}$ particles from $\mathrm{Al}$ matrix induced by tool-particle interaction occurring in the middle part of particles significantly deteriorates surface integrity due to cavity formation. Furthermore, $\mathrm{SiC}$ particle-tool edge interactions also have a great impact on machining force variations and residual stress distribution. FE simulations of the influence of $\mathrm{SiC}$ particle distribution demonstrate that it is easier to obtain a better machining surface quality of $\mathrm{SiCp} / \mathrm{Al}$ in cutting processes with a larger size distribution range.

Acknowledgements Funding was provided by National Natural Science Foundation of China (Grant No. 51761135106), Fundamental Research Funds for the Central Universities, Science Challenge Project (Grant Nos. TZ2018006-0201-02, TZ2018006-0205-02) and State Key Lab of Digital Manufacturing Equipment and Technology (Grant Nos. DMETKF 2018007, DMETKF2019016).

Open Access This article is licensed under a Creative Commons Attribution 4.0 International License, which permits use, sharing, adaptation, distribution and reproduction in any medium or format, as long as you give appropriate credit to the original author(s) and the source, provide a link to the Creative Commons licence, and indicate if changes were made. The images or other third party material in this article are included in the article's Creative Commons licence, unless indicated otherwise in a credit line to the material. If material is not included in the article's Creative Commons licence and your intended use is not permitted by statutory regulation or exceeds the permitted use, you will need to obtain permission directly from the copyright holder. To view a copy of this licence, visit http://creativecommons.org/licenses/by/4.0/.

\section{References}

1. Lee RS, Chen GA, Hwang BH (1995) Thermal and grinding induced residual stresses in a silicon carbide particle-reinforced aluminium metal matrix composite. Composites 26(6):425-429
2. Dandekar CR, Shin YC (2012) Modeling of machining of composite materials: a review. Int J Mach Tools Manuf 57:102-121

3. Li P, Ji XH, Xue KM (2018) Correlation between the thermal responses and microstructure patterns in aluminum-based silicon carbide composites ( $\mathrm{SiCp} / \mathrm{Al}$ ) consolidated by different high pressure torsion schemes. Mater Sci Eng Technol 49(9):1117-1124

4. Bai YC, Shi ZQ, Lee YJ, Wang H (2020) Optical surface generation on additively manufactured AlSiMg0.75 alloys with ultrasonic vibration-assisted machining. J Mater Process Technol 280:116597

5. http://www.matweb.com

6. Teng XY, Chen WQ, Huo DH, Shyha I, Lin C (2018) Comparison of cutting mechanism when machining micro and nanoparticles reinforced $\mathrm{SiC} / \mathrm{Al}$ metal matrix composites. Compos Struct 203:636-647

7. Cheung CF, Chan KC, To S, Lee WB (2002) Effect of reinforcement in ultra-precision machining of $\mathrm{A} 16061 / \mathrm{SiC}$ metal matrix composites. Scr Mater 47(2):77-82

8. Cheung CF, Lee WB (2000) A theoretical and experimental investigation of surface roughness formation in ultra-precision diamond turning. Int J Mach Tools Manuf 40(7):979-1002

9. Fathipour M, Zoghipour P, Tarighi J, Yousef R (2012) Investigation of reinforced SIC particles percentage on machining force of metal matrix composite. Mod Appl Sci 6(8):9-20

10. Nithiya Sandhiya YJ, Thamizharasan MM, Ajay Subramanyam BV, Vijay Sekar KS, Suresh Kumar S (2018) Finite element analysis of tool particle interaction, particle volume fraction, size, shape and distribution in machining of $\mathrm{A} 356 / \mathrm{SiCp}$. Mater Today Proc 5(8):16800-16806

11. Wang $\mathrm{T}$ (2015) Basic research on high volume milling of high volume fraction $\mathrm{SiCp} / \mathrm{Al}$ composite. Beijing Institute of Technology, Beijing

12. Lu SJ, Zhang JJ, Li ZQ, Zhang JG, Wang XH, Hartmaier A, Xu JF, Yan YD, Sun T (2020) Cutting path-dependent machinability of $\mathrm{SiCp} / \mathrm{Al}$ composite under multi-step ultra-precision diamond cutting. Chin J Aeronaut (in press)

13. Shao JC, Xiao BL, Wang QZ, Ma ZY, Yang K (2011) An enhanced FEM model for particle size dependent flow strengthening and interface damage in particle reinforced metal matrix composites. Compos Sci Technol 71(1):39-45

14. Pramanik A, Zhang LC, Arsecularatne JA (2007) An FEM investigation into the behavior of metal matrix composites: tool-particle interaction during orthogonal cutting. Int J Mach Tools Manuf 47(10):1497-1506

15. Fathipour M, Hamedi M, Yousefi R (2013) Numerical and experimental analysis of machining of $\mathrm{Al}(20 \mathrm{vol} \% \mathrm{SiC}) \mathrm{com}-$ posite by the use of ABAQUS software. Mater Sci Eng Technol 44(1):14-20

16. Umer U, Ashfaq M, Qudeiri JA, Hussein HMA, Danish SN, AlAhmari AR (2015) Modeling machining of particle-reinforced aluminum-based metal matrix composites using cohesive zone elements. Int J Adv Manuf Technol 78(5-8):1171-1179

17. Chen XL, Wang XB, Xie LJ, Wang T, Ma B (2018) Determining A16063 constitutive model for cutting simulation by inverse identification method. Int J Adv Manuf Technol 98(1-4):47-54

18. Mabrouki T, Girardin F, Asad M, Rigal J (2008) Numerical and experimental study of dry cutting for an aeronautic aluminium alloy (A2024-T351). Int J Mach Tools Manuf 48(11):1187-1197

19. Hibbitt, Karlsson, Sorensen (2001) ABAQUS/Explicit: user's manual. Hibbitt, Karlsson and Sorensen Incorporated

20. Wang YF, Liao WH, Yang K, Chen WQ, Liu TT (2018) Investigation on cutting mechanism of $\mathrm{SiCp} / \mathrm{Al}$ composites in precision turning. Int J Adv Manuf Technol 100(1-4):963-972

21. Dabade UA, Joshi SS, Balasubramaniam R, Bhanuprasad VV (2007) Surface finish and integrity of machined surfaces on $\mathrm{Al} /$ SiCp composites. J Mater Process Technol 192:166-174 